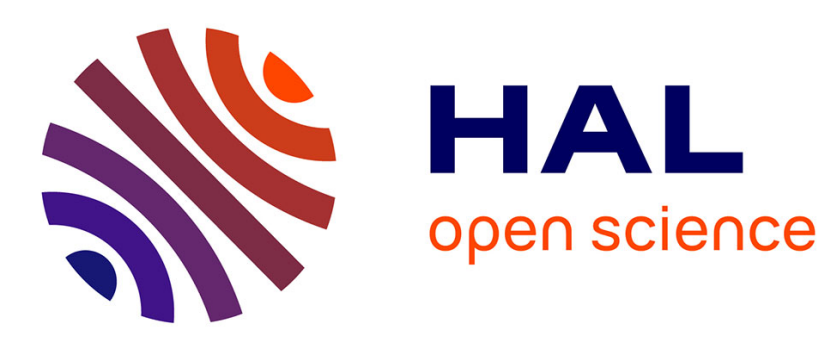

\title{
Measuring Myocardial Energetics with Cardiovascular Magnetic Resonance Spectroscopy
} Joevin Sourdon, Sabra C Lewsey, Michael Schär, Robert G Weiss

\section{To cite this version:}

Joevin Sourdon, Sabra C Lewsey, Michael Schär, Robert G Weiss. Measuring Myocardial Energetics with Cardiovascular Magnetic Resonance Spectroscopy. Heart Failure Clinics, 2021, 17 (1), pp.149 156. 10.1016/j.hfc.2020.08.011 . hal-03431249

\author{
HAL Id: hal-03431249 \\ https://hal.science/hal-03431249
}

Submitted on 16 Nov 2021

HAL is a multi-disciplinary open access archive for the deposit and dissemination of scientific research documents, whether they are published or not. The documents may come from teaching and research institutions in France or abroad, or from public or private research centers.
L'archive ouverte pluridisciplinaire HAL, est destinée au dépôt et à la diffusion de documents scientifiques de niveau recherche, publiés ou non, émanant des établissements d'enseignement et de recherche français ou étrangers, des laboratoires publics ou privés. 
Heart Fail Clin.2021 Jan;17(1):149-156. doi: 10.1016/j.hfc.2020.08.011

Measuring myocardial energetics with cardiovascular magnetic resonance spectroscopy

Joevin Sourdon, $\mathrm{PhD}^{1,2}$; Sabra C. Lewsey, $\mathrm{MD} \mathrm{MPH}^{2}$; Michael Schär $\mathrm{PhD}^{3}$;

Robert G. Weiss, MD²

\section{Affiliations}

${ }^{1}$ Aix-Marseille Université, CNRS, CRMBM, Marseille, France.

${ }^{2}$ Division of Cardiology, Department of Medicine, Johns Hopkins University School of Medicine, Baltimore, MD, US

${ }^{3}$ Division of Magnetic Resonance Research, Department of Radiology, Johns Hopkins University School of Medicine, Baltimore, MD, US

\section{Author Contact Information:}

Joevin Sourdon, CRMBM, Faculté de Médecine, 27 BVD Jean Moulin, 13005 Marseille, France ; joevin.sourdon@univ-amu.fr

Sabra C. Lewsey, Halsted 500, Johns Hopkins Hospital, 600 N. Wolfe Street, Baltimore, MD 21287, lewsey@jhmi.edu.Twitter:@docsabe

Michael Schär, Park 330, Johns Hopkins Hospital, 600 N. Wolfe Street, Baltimore, MD 21287, michael.schar@gmail.com

\section{Address for correspondence:}

Robert G. Weiss, MD

Blalock 544, Johns Hopkins Hospital

600 N. Wolfe St.

Baltimore, MD 21287-6568 
Phone: 410-955-1703

Email: rweiss@jhmi.edu

Disclosure Statement: The authors have no financial relationships to disclose.

Word Count: 4272 including references

\section{Key words}

Metabolism, energetics, cardiomyopathies, heart failure, cardiac magnetic resonance, spectroscopy.

\section{Key Points}

- Dysfunction of multiple important myocardial metabolic pathways and energetics occurs with several common cardiovascular diseases.

- Because myocardial metabolism fuels ongoing cardiac contractile function, metabolic and energetic abnormalities in the failing heart may contribute to contractile dysfunction, disease development, and progression.

- Cardiac magnetic resonance spectroscopy allows the non-invasive, non-destructive exploration of metabolism in the beating heart.

\section{Synopsis}

The heart has the highest energy demands per gram of any organ in the body and energy metabolism fuels normal contractile function. Metabolic inflexibility and impairment of myocardial energetics occur with several common cardiac diseases, including heart failure and in the ischemic heart. This review explores several decades of innovation in cardiac magnetic resonance spectroscopy modalities and their use to non-invasively identify and quantify metabolic derangements in the normal, failing, and diseased heart. The implications of this non- 
invasive modality for predicting significant clinical outcomes and guiding future investigation and therapies to improve patient care are discussed.

\section{Introduction}

This review summarizes the cardiac metabolic remodeling that occurs in major cardiac diseases and the advantage of quantifying metabolism noninvasively in the beating heart with cardiac magnetic resonance spectroscopy (CMRS).

\section{Primer on Myocardial Metabolism}

Most of myocardial chemical energy is derived from the oxidation of the three main substrates, free fatty acids (FFA), glucose and ketone bodies ${ }^{1}$. Glucose and FFA are catabolized into acetyl-CoA to enter the mitochondrial tricarboxylic acid (TCA, Krebs) cycle. ATP formation is then completed by mitochondrial oxidative phosphorylation. The creatine kinase (CK) reaction is the main cardiac energy reserve reaction which reversibly transfers the high energy phosphate (HEP) of ATP to creatine $(\mathrm{Cr})$ to form creatine phosphate $(\mathrm{PCr})$ :

$$
\mathrm{PCr}+\mathrm{ADP}+\mathrm{H}^{+} \underset{k f}{\stackrel{k r}{\leftarrow}} \mathrm{ATP}+\mathrm{Cr}
$$

Where $k_{r}$ is the reverse rate constant and $k_{f}$ is the forward rate constant of CK activity.

Myocardial bioenergetics have been defined by HEP levels and their turnover in tissue. Thus, the $\mathrm{CK}$ reaction by producing $\mathrm{PCr}$, may enhance intracellular delivery of high-energy phosphate from mitochondrial sites of ATP production to cytoplasmic sites of ATP utilization but CK is also thought to act as a temporal HEP buffer tightly maintaining high ATP and low ADP concentrations during changes in energy demand (Figure 1) $)^{2}$.

Remodeling of certain metabolic pathways, substrate preferences and PCr:ATP energy balance occur with several common cardiovascular diseases, including heart failure, and may contribute to disease development and progression ${ }^{3}$. Myocardial ATP turnover depends in large 
part on energy demand and thus in vitro studies may not always faithfully recapitulate the energetic profile of the in vivo contracting heart. Therefore, the non-destructive exploration and quantification of metabolism in the beating heart with cardiac CMRS offers unique and potentially powerful means to better understand the role of altered metabolism in cardiac diseases and develop novel diagnostic and therapeutic targets.

\section{Cardiac Magnetic Resonance Spectroscopy Principles}

CMRS allows the non-invasive measurement of proton $\left({ }^{1} \mathrm{H}\right)$-containing metabolites such as $\mathrm{Cr}$, carbon $\left({ }^{13} \mathrm{C}\right)$-containing metabolites from glucose and lipid metabolism, and phosphorus $\left({ }^{31} \mathrm{P}\right)$-containing metabolites such as $\mathrm{PCr}$ and ATP. Those nuclei have an intrinsic nuclear magnetic moment, which is called nuclear spin. These nuclear spins will be aligned with or against an applied magnetic field $\left(\mathrm{B}_{0}\right)$, leading to a macroscopic equilibrium magnetization $\left(\mathrm{M}_{0}\right)$ along $\mathrm{B}_{0}$. Radiofrequency $(\mathrm{RF})$ pulses can be used to perturb the alignment of $\mathrm{M}_{0}$, so called excitation. The excited magnetization will then precess around $\mathrm{B}_{0}$ and induce a measurable voltage in receiver coils tuned to the specific nucleus. The precession frequency depends on $\mathrm{B}_{0}$, the nucleus, and its chemical environment enabling the identification of different metabolites. The detected signal is transformed to a spectrum using the Fourier transformation to identify the different frequency components of the signal. In the spectrum, different metabolites are then identified by the frequency of their signal peaks, and the area under the peak reflects the concentration of that metabolite (Figure 2). Today, CMRS is typically performed using scanners with $\mathrm{B}_{0}$ of $4.7^{4}$ or $11.7^{5}$ tesla $(\mathrm{T})$ in cardiac preclinical applications and $1.5 \mathrm{~T}^{6}, 3 \mathrm{~T}^{7}$ or $7 \mathrm{~T}^{8}$ in clinical studies.

\section{3a. ${ }^{31}$ P-MRS}

${ }^{31} \mathrm{P}-\mathrm{MRS}$ is most commonly used in studies of myocardial energy metabolism and the techniques for spatial-localization often include either 1-, 2-, or 3-dimensional chemical shift 
imaging (CSI) or image-selected in vivo spectroscopy (ISIS). ${ }^{31} \mathrm{P}-\mathrm{MRS}$ is the only technique able to non-destructively measure HEP in the in vivo human heart (Figure 2).

The cardiac PCr/ATP ratio was the first myocardial energetic parameter measured with spatially-localized ${ }^{31} \mathrm{P}-\mathrm{MRS}^{6,9,10}$ and $\mathrm{PCr}$ is roughly twice as abundant as ATP in the healthy human heart. Absolute quantification of PCr and ATP concentrations can be accomplished by comparison to an external standard and the results do not assume that ATP is constant ${ }^{11,12,13}$. A summary of major ${ }^{31} \mathrm{P}-\mathrm{MRS}$ absolute phosphate metabolites render concentrations of $\mathrm{PCr}=$ $9.9 \pm 0.7$ and ATP $=6.0 \pm 0.5 \mu \mathrm{mol} / \mathrm{g}$ wet wt in the healthy human heart ${ }^{11-20,7}$.

Furthermore, measurement of uni-directional ATP synthesis through the $\mathrm{CK}$ reaction ("'CK flux") with ${ }^{31} \mathrm{P}$ saturation transfer MRS offers critical insight into energy turnover in cardiomyocytes. The conventional saturation transfer approach consists of saturating the magnetization of $\gamma$-P of ATP involved in the chemical exchange with $\mathrm{PCr}$, which leads to a decrease of the $\mathrm{PCr}$ magnetization $\left(\mathrm{M}_{0}{ }^{\prime}\right)$ proportional to pseudo first-order rate constant, $k_{f}$, and calculated as follows:

$$
k_{f}=\frac{1}{T_{1}{ }^{\prime}}\left(1-\frac{M_{0}{ }^{\prime}}{M_{0}}\right)
$$

With $T_{1}$ ' being the longitudinal relaxation time and $\mathrm{M}_{0}$ ' and $\mathrm{M}_{0}$ the equilibrium magnetizations of PCr while $\gamma$-ATP is saturated or unsaturated, respectively. With conventional saturation techniques the determination of $\mathrm{T}_{1}$ ' is very time consuming, but $\sim 15$ years ago accelerated approaches were developed and enabled the first measurements of ATP synthesis in the human heart ${ }^{17}$. Multiple techniques have since been used to calculate $k_{f}\left(\sim 0.33 \sec ^{-1}\right)^{17,21-24}$, and subsequently CK flux that equals $k_{f} \times[\mathrm{PCr}](\sim 3.4 \mu \mathrm{mol} / \mathrm{g} / \mathrm{sec})$ in the healthy human heart ${ }^{17,23,24}$. ${ }^{31} \mathrm{P}-\mathrm{MRS}$ can also be used to noninvasively measure inorganic phosphate (Pi), to quantify cytosolic ADP (from the $\mathrm{CK}$ equilibrium reaction), intracellular $\mathrm{pH}$ (from the chemical shift of Pi relative to PCr) and the free-energy change of ATP hydrolysis $\left[-\Delta G_{\mathrm{ATP}}(\mathrm{kJ} / \mathrm{mol})\right]^{17,25}$. While these approaches have been used extensively in isolated, perfused hearts, they have been less 
successful and less commonly implemented in the human heart, due to overlap of blood 2,3diacylglycerol (DPG) resonances with the Pi resonance used for most calculations. The peak overlap may be overcome by the increased chemical shift dispersion at $7 \mathrm{~T}^{8,26}$.

\section{3b. ${ }^{1} \mathrm{H}-\mathrm{MRS}$}

Spatially-localized ${ }^{1} \mathrm{H}$-MRS has been used to measure a number of metabolites ${ }^{27}$ but in vivo human studies are primarily limited to measuring myocardial triglycerides ${ }^{28,29}$ and total creatine ${ }^{30}$. Unlike ${ }^{13} \mathrm{C}$ and ${ }^{31} \mathrm{P}-\mathrm{MRS}$ which require specially-tuned excitation and detection coils, conventional imaging surface coils can be used for ${ }^{1} \mathrm{H}-\mathrm{MRS}$.

\section{3c. ${ }^{13} \mathrm{C}-\mathrm{MRS}$}

Although ${ }^{13} \mathrm{C}$-MRS is a powerful technique used to study carbon substrate metabolism in animal hearts, it is rarely used in human hearts due to the low sensitivity of the ${ }^{13} \mathrm{C}$ nucleus and the expense of ${ }^{13} \mathrm{C}$-labeled substrates. However, dynamic nuclear polarization, an innovative technique, theoretically improves sensitivity 10,000-fold ${ }^{31}$. Metabolites labeled with

${ }^{13} \mathrm{C}$ are hyperpolarized in a polarizer and then injected into a living system ${ }^{32,33}$. Although the entire process is complex in practice and the hyperpolarization is short-lived, this technique allows real time assessment of the Krebs $\mathrm{Cycle}^{34}$ and may soon be applicable in people ${ }^{35}$.

\section{Applications}

\section{4a. Heart failure risk factors: Ischemia, Infarction, and Diabetes}

Early ${ }^{31} \mathrm{P}-\mathrm{MRS}$ studies in isolated animal hearts during acute, severe ischemia demonstrated rapid and significant decreases in PCr and increases in Pi with initially preserved $\mathrm{ATP}^{36,37,38}$. ATP decline appears after prolonged ischemia and PCr depletion, but the PCr signal recovers rapidly during reperfusion in viable tissue ${ }^{39}$.

${ }^{31} \mathrm{P}-\mathrm{MRS}$ has also been utilized in vivo to detect energetic changes during myocardial ischemia in humans ${ }^{40}$. During isometric handgrip exercise (IHE) stress, spatially-localized ${ }^{31} \mathrm{P}$ - 
MRS detected significant stress-induced reductions in cardiac PCr/ATP in patients with significant coronary artery disease, but not in healthy subjects or those with non-ischemic disease. Furthermore, stress-induced myocardial PCr/ATP decline resolved after successful revascularization ${ }^{40}$. These observations of IHE stress-induced declines in cardiac PCr/ATP in CAD patients were reproduced by others ${ }^{41,42}$.

The chronic disruption of myocardial metabolism following infarction has been identified with ${ }^{31} \mathrm{P}-\mathrm{MRS}$ whereby viable myocardium (more $\mathrm{PCr}$ and $\left.\mathrm{ATP}\right)^{12,43}$, ischemic without infarction (intermediate PCr and $\mathrm{ATP})^{12}$, and scarred post-infarct (less $\mathrm{PCr}$ and ATP) ${ }^{12,43}$ myocardium can be distinguished ${ }^{43} .{ }^{1} \mathrm{H}-\mathrm{MRS}$ can detect lower creatine in infarcted areas throughout canine ${ }^{44}$ and human hearts ${ }^{30}$ and ${ }^{31} \mathrm{P}-\mathrm{MRS}$ saturation transfer techniques identified reduced CK flux in infarcted myocardial regions ${ }^{19}$.

${ }^{31} \mathrm{P}-\mathrm{MRS}$ has identified reduced PCr/ATP in myocardium of patients with risk factors for heart failure such as those with hypertension with diastolic dysfunction ${ }^{45}$, type 2 diabetes ${ }^{46,47}$, type 1 diabetes ${ }^{48}$ and/or obesity ${ }^{49}$. Moreover, ${ }^{1} \mathrm{H}-\mathrm{MRS}$ assessed decreased creatine in the myocardium of various nonischemic heart diseases ${ }^{50}$.

\section{4b. Heart Failure}

Heart failure (HF) is often defined as the inability of the heart to pump sufficient blood to meet the demands of the body (or to do so at elevated filling pressures) and the decades old energy-deprivation hypothesis of $\mathrm{HF}^{51}$ posits that the failing heart has insufficient metabolic energy to fuel normal contraction. The emergence of MRS measures of energy metabolism in the beating heart have addressed several gaps in this theory.

Early animal and human tissue studies ${ }^{52}$ supported the energy-starvation hypothesis whereby progressive and insidious loss of ATP with a loss of the total purine pool, most evident when heart failure is severe, were reported as well as an early reduction in the creatine pool ${ }^{53}$. Isolated human myocardial tissues are difficult to rapidly obtain, especially in patients with early, mild 
disease, but seminal studies demonstrated significant reductions in ATP, total adenine nucleotides, and nicotinamide adenine dinucleotide (NAD) ${ }^{54}$, in creatine content ${ }^{55}$ and in CK activity ${ }^{56}$ in patients with heart failure. Given the invasive nature of tissue biopsies, ${ }^{31} \mathrm{P}$ - and ${ }^{1} \mathrm{H}-\mathrm{MRS}$ have been the primary methodologies to better understand cardiac metabolism in $\mathrm{HF}$ under physiologic conditions. Several early groups reported a $20 \%-30 \%$ reduction in cardiac PCr/ATP at rest in systolic HF and dilated cardiomyopathy (DCM) patients ${ }^{57-61}$. The subsequent ability to noninvasively quantify HEP concentrations ${ }^{11,13}$ revealed that the PCr/ATP ratio, in fact, may underestimate the reductions observed in absolute concentration of $\mathrm{PCr}$, especially in end-stage heart failure. Cardiac ATP flux through CK is reduced by $\sim 50 \%$ in patients with heart failure and non-ischemic dilated cardiomyopathy ${ }^{17}$ and by nearly $70 \%$ in patients with left ventricular hypertrophy and heart failure ${ }^{18}$. Cardiac CK flux declines before ATP loss in human HF and the reduction is greater than changes in absolute metabolite concentrations or PCr/ATP. In addition, extensive energetic abnormalities, including derangements in HEP metabolism ${ }^{6,62}$, reduced CK flux ${ }^{56,17,18,63,64}$, and lipid accumulation ${ }^{65,66}$ have been reported in human heart failure.

An early study ${ }^{58}$ demonstrated lower PCr/ATP in aortic valve disease patients with symptomatic heart failure than in those without. Cardiac PCr/ATP was shown to correlate with New York Heart Association functional class of symptom severity in DCM patients, and reported to improve or even normalize with implementation of conventional medical therapy over three months (ACE-inhibitors; Beta-blockers) ${ }^{59}$. In the late 1990s, low cardiac PCr/ATP was found to predict all-cause and cardiovascular mortality in DCM patients ${ }^{67}$. More recently, rates of ATP synthesis through $\mathrm{CK}$, rather than $\mathrm{PCr} / \mathrm{ATP}$, independently predicted heart failure related events including transplant and cardiovascular mortality in HF patients on contemporary therapy ${ }^{63}$. More recently CK flux in heart failure patients was shown to correlate with myocardial mechanical power and mechanical efficiency, suggesting that CK energy 
deprivation is closely associated with cardiac dysfunction ${ }^{64}$. Thus, myocardial energetic abnormalities not only occur in heart failure and are related to symptom and functional severity, but predict subsequent adverse cardiovascular outcomes.

Eighty years of cardiac metabolic research has collectively improved our understanding of energetic dysfunction and its contribution to the failing human heart, however many questions remain. Pathways of future investigation of energetics in heart failure include 1) understanding metabolic differences in heart failure with reduced versus preserved ejection fraction, 2) defining biochemical remodeling and myocardial mitochondrial function in a new age of conventional therapy, and 3) developing novel metabolic drug targets.

\section{Limitations and Perspectives}

Spatial resolution and depth of detection can limit the application of ${ }^{31} \mathrm{P}-\mathrm{MRS}$ for heterogenous diseases such as myocardial infarction. Higher magnetic field strength in clinical applications (7T) will improve signal to noise ratio, accelerate acquisitions, and may allow the exploration of Pi and energetics in small myocardial regions. In addition, the development of chemical exchange saturation transfer and hyperpolarized ${ }^{13} \mathrm{C}$-MRS techniques are very promising techniques to map in vivo free creatine, $\mathrm{PCr}$ and assess pyruvate dehydrogenase flux. A current gap in the understanding of bioenergetics in heart failure is the evaluation of individuals with heart failure with preserved ejection fraction.

\section{Summary/Discussion}

Myocardial energetics are impaired in systolic heart failure and acute ischemia. Metabolic remodeling has been demonstrated in progressive heart failure stages, chronic infarction, and even in conditions associated with increased heart failure risk, including hypertension, diabetes, and obesity. Some energetic abnormalities have been shown to correlate 
with symptom severity and significant heart failure outcomes, including mortality. CMRS has been fundamental in building our understanding of energy-deprivation in the failing heart and will likely continue to be a pioneering technology in the development and evaluation of new era heart failure therapeutics with focused metabolic targets.

\section{References}

1. Stanley WC., Recchia FA., Lopaschuk GD. Myocardial substrate metabolism in the normal and failing heart. Physiological Reviews 2005;85(3):1093-129. Doi: 10.1152/physrev.00006.2004.

2. Saks V., Dzeja P., Schlattner U., et al. Cardiac system bioenergetics: metabolic basis of the Frank-Starling law. The Journal of Physiology 2006;571(Pt 2):253-73. Doi: 10.1113/jphysiol.2005.101444.

3. Neubauer S. The Failing Heart - An Engine Out of Fuel. N Engl J Med 2007;356(11):114051. Doi: 10.1056/NEJMra063052.

4. Chacko VP., Aresta F., Chacko SM., et al. MRI/MRS assessment of in vivo murine cardiac metabolism, morphology, and function at physiological heart rates. American Journal of Physiology-Heart and Circulatory Physiology 2000;279(5):H2218-24. Doi: 10.1152/ajpheart.2000.279.5.H2218.

5. Perrine SA., Michaels MS., Ghoddoussi F., et al. Cardiac effects of MDMA on the metabolic profile determined with $1 \mathrm{H}$-magnetic resonance spectroscopy in the rat. Nuclear Magnetic Resonance in Biomedicine 2009;22(4):419-25. Doi: 10.1002/nbm.1352.

6. Bottomley PA. Noninvasive study of high-energy phosphate metabolism in human heart by depth-resolved 31P NMR spectroscopy. Science 1985;229(4715):769-72. Doi: 10.1126/science.4023711. 
7. El-Sharkawy A-MM., Gabr RE., Schär M., et al. Quantification of human high-energy phosphate metabolite concentrations at $3 \mathrm{~T}$ with partial volume and sensitivity corrections. Nuclear Magnetic Resonance in Biomedicine 2013;26(11):1363-71. Doi: 10.1002/nbm.2961. 8. Rodgers CT., Clarke WT., Snyder C., et al. Human cardiac 31P magnetic resonance spectroscopy at 7 Tesla. Magnetic Resonance in Medicine 2014;72(2):304-15. Doi: 10.1002/mrm.24922.

9. Bottomley PA., Herfkens RJ., Smith LS., et al. Noninvasive detection and monitoring of regional myocardial ischemia in situ using depth-resolved 31P NMR spectroscopy. Proceedings of the National Academy of Sciences USA 1985;82(24):8747-51. Doi: 10.1073/pnas.82.24.8747.

10. Blackledge MJ., Rajagopalan B., Oberhaensli RD., et al. Quantitative studies of human cardiac metabolism by 31P rotating-frame NMR. Proceedings of the National Academy of Sciences U S A 1987;84(12):4283-7.

11. Bottomley PA., Hardy CJ., Roemer PB. Phosphate metabolite imaging and concentration measurements in human heart by nuclear magnetic resonance. Magnetic Resonance in Medicine 1990;14(3):425-34. Doi: 10.1002/mrm.1910140302.

12. Yabe T., Mitsunami K., Inubushi T., et al. Quantitative measurements of cardiac phosphorus metabolites in coronary artery disease by $31 \mathrm{P}$ magnetic resonance spectroscopy. Circulation 1995;92(1):15-23. Doi: 10.1161/01.cir.92.1.15.

13. Bottomley PA., Atalar E., Weiss RG. Human cardiac high-energy phosphate metabolite concentrations by 1D-resolved NMR spectroscopy. Magnetic Resonance in Medicine 1996;35(5):664-70. Doi: 10.1002/mrm.1910350507.

14. Okada M., Mitsunami K., Inubushi T., et al. Influence of aging or left ventricular hypertrophy on the human heart: Contents of phosphorus metabolites measured by 31P MRS. Magnetic Resonance in Medicine 1998;39(5):772-82. Doi: 10.1002/mrm.1910390515. 
15. Meininger M., Landschütz W., Beer M., et al. Concentrations of human cardiac phosphorus metabolites determined by SLOOP 31P NMR spectroscopy. Magnetic Resonance in Medicine 1999;41(4):657-63. Doi 10.1002/(SICI)1522-2594(199904)41:4<657::AIDMRM3>3.0.CO;2-I.

16. Schneider-Gold C., Beer M., Köstler H., et al. Cardiac and skeletal muscle involvement in myotonic dystrophy type 2 (DM2): a quantitative 31P-MRS and MRI study. Muscle \& Nerve 2004;30(5):636-44. Doi: 10.1002/mus.20156.

17. Weiss RG., Gerstenblith G., Bottomley PA. ATP flux through creatine kinase in the normal, stressed, and failing human heart. Proceedings of the National Academy of Sciences USA 2005;102(3):808-13. Doi: 10.1073/pnas.0408962102.

18. Smith CS., Bottomley PA., Schulman SP., et al. Altered Creatine Kinase Adenosine Triphosphate Kinetics in Failing Hypertrophied Human Myocardium. Circulation 2006;114(11):1151-8. Doi: 10.1161/CIRCULATIONAHA.106.613646.

19. Bottomley PA., Wu KC., Gerstenblith Gy, et al. Reduced Myocardial Creatine Kinase Flux in Human Myocardial Infarction. Circulation 2009;119(14):1918-24. Doi: 10.1161/CIRCULATIONAHA.108.823187.

20. Abraham MR., Bottomley PA., Dimaano VL., et al. Creatine Kinase Adenosine Triphosphate and Phosphocreatine Energy Supply in a Single Kindred of Patients With Hypertrophic Cardiomyopathy. Am J Cardiol 2013;112(6):861-6. Doi: 10.1016/j.amjcard.2013.05.017.

21. Schär M., El-Sharkawy A-MM., Weiss RG., et al. Triple repetition time saturation transfer (TRiST) 31P spectroscopy for measuring human creatine kinase reaction kinetics. Magnetic Resonance in Medicine 2010;63(6):1493-501. Doi: 10.1002/mrm.22347. 
22. Schär M., Gabr RE., El-Sharkawy A-MM., et al. Two repetition time saturation transfer (TwiST) with spill-over correction to measure creatine kinase reaction rates in human hearts. Journal of Cardiovascular Magnetic Resonance 2015;17(1). Doi: 10.1186/s12968-015-0175-4. 23. Bashir A., Gropler R. Reproducibility of creatine kinase reaction kinetics in human heart: a 31P time-dependent saturation transfer spectroscopy study. Nuclear Magnetic Resonance in Biomedicine 2014;27(6):663-71. Doi: 10.1002/nbm.3103.

24. Clarke WT., Robson MD., Neubauer S., et al. Creatine kinase rate constant in the human heart measured with 3D-localization at 7 tesla. Magnetic Resonance in Medicine 2017;78(1):20-32. Doi: 10.1002/mrm.26357.

25. Hirsch GA., Bottomley PA., Gerstenblith G., et al. Allopurinol acutely increases adenosine triphospate energy delivery in failing human hearts. J Am Coll Cardiol 2012;59(9):802-8. Doi: 10.1016/j.jacc.2011.10.895.

26. Valkovič L., Clarke WT., Schmid AI., et al. Measuring inorganic phosphate and intracellular $\mathrm{pH}$ in the healthy and hypertrophic cardiomyopathy hearts by in vivo 7T 31Pcardiovascular magnetic resonance spectroscopy. Journal of Cardiovascular Magnetic Resonance 2019;21(1):19. Doi: 10.1186/s12968-019-0529-4.

27. Keller AM., Sorce DJ., Sciacca RR., et al. Very rapid lactate measurement in ischemic perfused hearts using $1 \mathrm{H}$ MRS continuous negative echo acquisition during steady-state frequency selective excitation. Magnetic Resonance in Medicine 1988;7(1):65-78. Doi: 10.1002/mrm.1910070108.

28. Reingold JS., McGavock JM., Kaka S., et al. Determination of triglyceride in the human myocardium by magnetic resonance spectroscopy: reproducibility and sensitivity of the method. American Journal of Physiology-Endocrinology and Metabolism 2005;289(5):E935939. Doi: 10.1152/ajpendo.00095.2005. 
29. Hammer S., van der Meer RW., Lamb HJ., et al. Progressive Caloric Restriction Induces Dose-Dependent Changes in Myocardial Triglyceride Content and Diastolic Function in Healthy Men. J Clin Endocrinol Metab 2008;93(2):497-503. Doi: 10.1210/jc.2007-2015.

30. Bottomley PA., Weiss RG. Non-invasive magnetic-resonance detection of creatine depletion in non-viable infarcted myocardium. Lancet 1998;351(9104):714-8. Doi: 10.1016/S0140-6736(97)06402-7.

31. Ardenkjaer-Larsen JH., Fridlund B., Gram A., et al. Increase in signal-to-noise ratio of > 10,000 times in liquid-state NMR. Proceedings of the National Academy of Sciences USA 2003;100(18):10158-63. Doi: 10.1073/pnas.1733835100.

32. Golman K., Petersson JS., Magnusson P., et al. Cardiac metabolism measured noninvasively by hyperpolarized 13C MRI. Magnetic Resonance in Medicine 2008;59(5):1005-13. Doi: 10.1002/mrm.21460.

33. Schroeder MA., Clarke K., Neubauer S., et al. Hyperpolarized Magnetic Resonance: A Novel Technique for the In Vivo Assessment of Cardiovascular Disease. Circulation 2011;124(14):1580-94. Doi: 10.1161/CIRCULATIONAHA.111.024919.

34. Schroeder MA., Atherton HJ., Ball DR., et al. Real-time assessment of Krebs cycle metabolism using hyperpolarized 13C magnetic resonance spectroscopy. FASEB Journal 2009;23(8):2529-38. Doi: 10.1096/fj.09-129171.

35. Rider OJ., Tyler DJ. Clinical implications of cardiac hyperpolarized magnetic resonance imaging. Journal of Cardiovascular Magnetic Resonance 2013;15:93. Doi: 10.1186/1532429X-15-93.

36. Hollis DP., Nunnally RL., Taylor GJ., et al. Phosphorus nuclear magnetic resonance studies of heart physiology. Journal of Magnetic Resonance (1969) 1978;29(2):319-30. Doi: $10.1016 / 0022-2364(78) 90156-7$. 
37. Jacobus WE., Taylor GJ., Hollis DP., et al. Phosphorus nuclear magnetic resonance of perfused working rat hearts. Nature 1977;265(5596):756-8. Doi: 10.1038/265756a0.

38. Garlick PB., Radda GK., Seeley PJ. Studies of acidosis in the ischaemic heart by phosphorus nuclear magnetic resonance. Biochemical Journal 1979;184(3):547-54. Doi: $10.1042 / \mathrm{bj} 1840547$.

39. Wolfe CL., Moseley ME., Wikstrom MG., et al. Assessment of myocardial salvage after ischemia and reperfusion using magnetic resonance imaging and spectroscopy. Circulation 1989;80(4):969-82. Doi: 10.1161/01.cir.80.4.969.

40. Weiss RG., Bottomley PA., Hardy CJ., et al. Regional Myocardial Metabolism of HighEnergy Phosphates during Isometric Exercise in Patients with Coronary Artery Disease.

N Engl J Med 1990;323(23):1593-600. Doi: 10.1056/NEJM199012063232304.

41. Buchthal SD., den Hollander JA., Merz CN., et al. Abnormal myocardial phosphorus-31 nuclear magnetic resonance spectroscopy in women with chest pain but normal coronary angiograms. N Engl J Med 2000;342(12):829-35. Doi: 10.1056/NEJM200003233421201.

42. Yabe T., Mitsunami K., Okada M., et al. Detection of myocardial ischemia by 31P magnetic resonance spectroscopy during handgrip exercise. Circulation 1994;89(4):1709-16. Doi: 10.1161/01.cir.89.4.1709.

43. Friedrich J., Apstein CS., Ingwall JS. 31P nuclear magnetic resonance spectroscopic imaging of regions of remodeled myocardium in the infarcted rat heart. Circulation 1995;92(12):3527-38. Doi: 10.1161/01.cir.92.12.3527.

44. Bottomley PA., Weiss RG. Noninvasive localized MR quantification of creatine kinase metabolites in normal and infarcted canine myocardium. Radiology 2001;219(2):411-8. Doi: 10.1148/radiology.219.2.r01ma39411. 
45. Lamb HJ., Beyerbacht HP., van der Laarse A., et al. Diastolic dysfunction in hypertensive heart disease is associated with altered myocardial metabolism. Circulation 1999;99(17):22617. Doi: 10.1161/01.cir.99.17.2261.

46. Scheuermann-Freestone M., Madsen PL., Manners D., et al. Abnormal cardiac and skeletal muscle energy metabolism in patients with type 2 diabetes. Circulation 2003;107(24):3040-6. Doi: 10.1161/01.CIR.0000072789.89096.10.

47. Diamant M., Lamb HJ., Groeneveld Y., et al. Diastolic dysfunction is associated with altered myocardial metabolism in asymptomatic normotensive patients with well-controlled type 2 diabetes mellitus. J Am Coll Cardiol 2003;42(2):328-35. Doi: 10.1016/s07351097(03)00625-9.

48. Shivu GN, Phan T.T., Abozguia K., et al. Relationship Between Coronary Microvascular Dysfunction and Cardiac Energetics Impairment in Type 1 Diabetes Mellitus. Circulation 2010;121(10):1209-15. Doi: 10.1161/CIRCULATIONAHA.109.873273.

49. Rider OJ., Francis JM., Ali MK., et al. Effects of catecholamine stress on diastolic function and myocardial energetics in obesity. Circulation 2012;125(12):1511-9. Doi: 10.1161/CIRCULATIONAHA.111.069518.

50. Nakae I., Mitsunami K., Matsuo S., et al. Myocardial creatine concentration in various nonischemic heart diseases assessed by $1 \mathrm{H}$ magnetic resonance spectroscopy. Circulation Journal 2005;69(6):711-6. Doi: 10.1253/circj.69.711.

51. Herrmann G., Decherd GM., The Chemical Nature of Heart Failure. Ann Intern Med 1939;12(8):1233. Doi: 10.7326/0003-4819-12-8-1233.

52. Olson RE., Schwartz WB. Myocardial metabolism in congestive heart failure. Medicine (Baltimore) 1951;30(1):21-41. Doi: 10.1097/00005792-195102000-00002. 
53. Shen W., Asai K., Uechi M., et al. Progressive loss of myocardial ATP due to a loss of total purines during the development of heart failure in dogs: a compensatory role for the parallel loss of creatine. Circulation 1999;100(20):2113-8. Doi: 10.1161/01.cir.100.20.2113.

54. Starling RC., Hammer DF., Altschuld RA. Human myocardial ATP content and in vivo contractile function. Molecular and Cellular Biochemistry 1998;180(1):171-7. Doi: 10.1023/A:1006876031121.

55. Ingwall JS., Kramer MF., Fifer MA., et al. The creatine kinase system in normal and diseased human myocardium. N Engl J Med 1985;313(17):1050-4. Doi: 10.1056/NEJM198510243131704.

56. Nascimben L., Ingwall JS., Pauletto P., et al. Creatine kinase system in failing and nonfailing human myocardium. Circulation 1996;94(8):1894-901. Doi: 10.1161/01.cir.94.8.1894.

57. Hardy CJ., Weiss RG., Bottomley PA., et al. Altered myocardial high-energy phosphate metabolites in patients with dilated cardiomyopathy. Am Heart J 1991;122(3 Pt 1):795-801. Doi: 10.1016/0002-8703(91)90527-o.

58. Conway MA., Allis J., Ouwerkerk R., et al. Detection of low phosphocreatine to ATP ratio in failing hypertrophied human myocardium by $31 \mathrm{P}$ magnetic resonance spectroscopy. Lancet 1991;338(8773):973-6. Doi: 10.1016/s0140-6736(91)91838-L.

59. Neubauer S., Krahe T., Schindler R., et al. 31P magnetic resonance spectroscopy in dilated cardiomyopathy and coronary artery disease. Altered cardiac high-energy phosphate metabolism in heart failure. Circulation 1992;86(6):1810-8. Doi: 10.1161/01.CIR.86.6.1810. 60. Masuda Y., Tateno Y., Ikehira H., et al. High-energy phosphate metabolism of the myocardium in normal subjects and patients with various cardiomyopathies--the study using ECG gated MR spectroscopy with a localization technique. Japanese Circulation Journal 1992;56(6):620-6. Doi: 10.1253/jcj.56.620. 
61. de Roos A., Doornbos J., Luyten PR., et al. Cardiac metabolism in patients with dilated and hypertrophic cardiomyopathy: assessment with proton-decoupled P-31 MR spectroscopy. Journal of Magnetic Resonance Imaging 1992;2(6):711-9. Doi: 10.1002/jmri.1880020616.

62. Buser PT., Camacho SA., Wu ST., et al. The effect of dobutamine on myocardial performance and high-energy phosphate metabolism at different stages of heart failure in cardiomyopathic hamsters: a 31P MRS study. Am Heart J 1989;118(1):86-91. Doi: 10.1016/0002-8703(89)90076-8.

63. Bottomley PA., Panjrath GS., Lai S., et al. Metabolic rates of ATP transfer through creatine kinase (CK Flux) predict clinical heart failure events and death. Science Translational Medicine 2013;5(215):215re3. Doi: 10.1126/scitranslmed.3007328.

64. Gabr RE., El-Sharkawy A-MM., Schär M., et al. Cardiac work is related to creatine kinase energy supply in human heart failure: a cardiovascular magnetic resonance spectroscopy study. Journal of Cardiovascular Magnetic Resonance 2018;20(1):81. Doi: 10.1186/s12968-0180491-6.

65. Sharma S., Adrogue JV., Golfman L., et al. Intramyocardial lipid accumulation in the failing human heart resembles the lipotoxic rat heart. FASEB Journal 2004;18(14):1692-700. Doi: 10.1096/fj.04-2263com.

66. Nakae I., Mitsunami K., Yoshino T., et al. Clinical features of myocardial triglyceride in different types of cardiomyopathy assessed by proton magnetic resonance spectroscopy: comparison with myocardial creatine. Journal of Cardiac Failure 2010;16(10):812-22. Doi: 10.1016/j.cardfail.2010.05.006.

67. Neubauer S., Horn M., Cramer M., et al. Myocardial phosphocreatine-to-ATP ratio is a predictor of mortality in patients with dilated cardiomyopathy. Circulation 1997;96(7):2190-6. Doi: 10.1161/01.cir.96.7.2190. 
68. Schlattner U., Tokarska-Schlattner M., Wallimann T. Metabolite Channeling: Creatine Kinase Microcompartments. In: Lennarz WJ, and Lane MD, editors. Encyclopedia of Biological Chemistry (Second Edition). Waltham: Academic Press; 2013. p. 80-5.

69. Ingwall JS., Weiss RG. Is the failing heart energy starved? On using chemical energy to support cardiac function. Circulation Research 2004;95(2):135-45. Doi: 10.1161/01.RES.0000137170.41939.d9. 


\section{Figure}

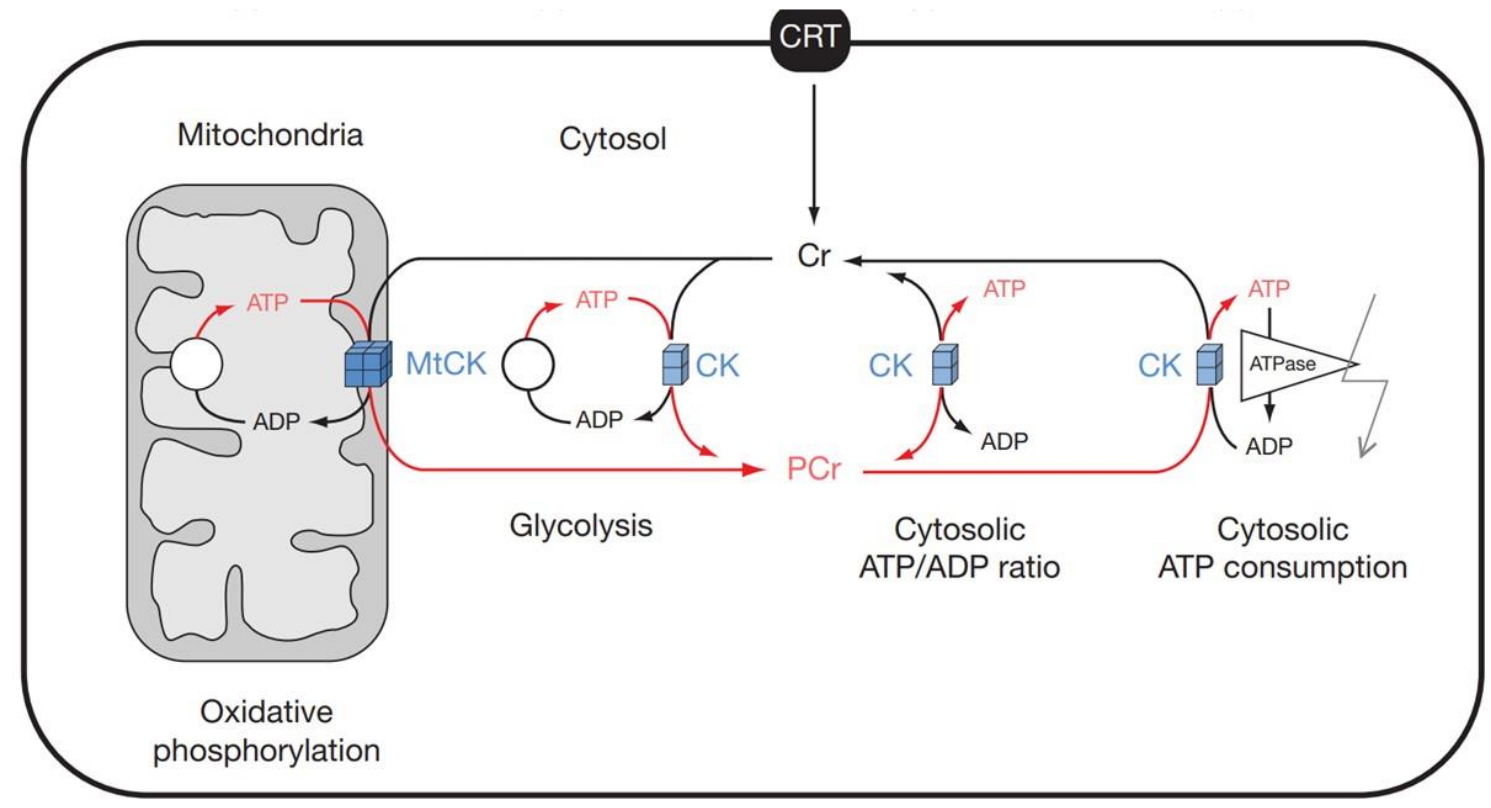

Figure 1: Representation of myocardial energy transport. The CK energy shuttle theoretically provides ATP from mitochondria to the sites of consumption. This includes two main isoforms of $\mathrm{CK}$, mitochondrial (MtCK) and cytoplasmic. Creatine is taken up from blood through $\mathrm{Cr}$ transporter (CRT). Adapted from Schlattner et al ${ }^{68}$ with permission. 


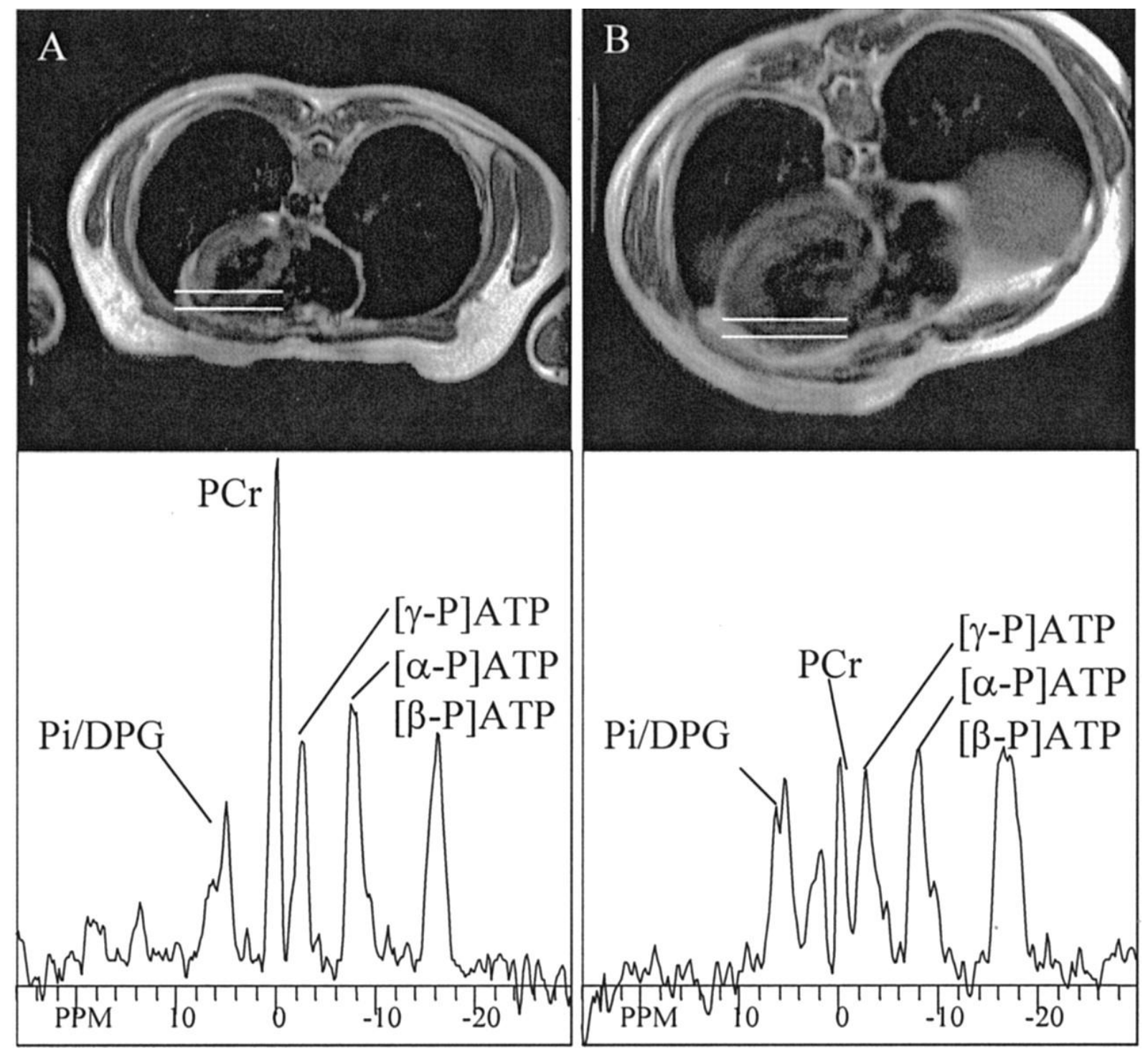

Figure 2. Comparison of spatially localized ${ }^{31} \mathrm{P}-\mathrm{MRS}$ of a healthy volunteer (A) and a patient with DCM with significant reduction of PCr (B). Upper images show the 1D CSI localization of ${ }^{31} \mathrm{P}-\mathrm{MRS}$ (anterior left ventricular wall). The peaks of the spectra (bottom panel) show the combination of inorganic phosphate (Pi) and 2,3-diphosphoglycerate (DPG), phosphodiesters, PCr, $\gamma$-ATP, $\beta$-ATP and $\alpha$-ATP. Fom Ingwall and Weiss ${ }^{69}$ with permission. 